\title{
The Investigation of Microwave-Assisted Greener Synthesis of Ag/Ti/Zn Trimetallic Nanoparticles and Carbon Quantum Dots Nanocomposites in the Application of Solar Cell
}

\author{
Meet A. Moradiya ${ }^{1, * \mathbb{D}}$, Pradeep Kumar Khiriya ${ }^{1}{ }^{\mathbb{D}}$, Gagan Kant Tripathi ${ }^{1}$, Priyavand Bundela ${ }^{1}$, \\ Purnima Swarup Khare ${ }^{1}$ (D) \\ 1 School of Nanotechnology, Rajiv Gandhi Proudyogiki Vishwavidyalaya, Bhopal, Madhya Pradesh, India \\ * Correspondence: meetmoradiya2812@gmail.com (M.A.M.);
}

Scopus Author ID 57217979707

Received: 3.05.2021; Revised: 15.06.2021; Accepted: 18.06.2021; Published: 27.06.2021

\begin{abstract}
In this communication, we report a greener microwave method for synthesizing $\mathrm{Ag} / \mathrm{Ti} / \mathrm{Zn}$ trimetallic nanoparticles and carbon quantum dots nanocomposites (Ag/Ti/Zn TNPs and CQDs NCs). The morphology, topography, and size of the Ag/Ti/Zn TNPs and CQDs nanocomposites were determined using scanning electron microscopy (SEM) and transmission electron microscopy (TEM) analysis. The optical properties of the as-synthesized Ag/Ti/Zn TNPs and CQDs NCs were examined using UV-Vis spectroscopy and bandgap analysis. Finally, the Ag/Ti/Zn TNPs and CQDs NCs were fabricated by microwave-assisted greener synthesis, which was used as a photosensitizer, the copper plate as a counter electrode, and polysulfide as an electrolyte was assembled into the solar cell. The natural pigments extracted from the fruit of Solanum lycopersicium extract were used in Ag/Ti/Zn TNPs and CQDs NCs based solar cells. The as-fabricated solar cell's conversion efficiency was $5.47 \%$ with a $\mathrm{V}_{\mathrm{oc}}$ of $0.74 \mathrm{~V}, \mathrm{~J}_{\mathrm{sc}}$ of $12.1 \mathrm{~mA} / \mathrm{cm}^{2}$, and an FF of 0.60 . Thus, this study highlights that the use of Ag/Ti/Zn TNPs and CQDs NCs has the great potential to be used as a photosensitizer.
\end{abstract}

Keywords: green synthesis; trimetallic nanoparticles; carbon quantum dots; nanocomposites; solar cell.

(C) 2021 by the authors. This article is an open-access article distributed under the terms and conditions of the Creative Commons Attribution (CC BY) license (https://creativecommons.org/licenses/by/4.0/).

\section{Introduction}

The global energy demand for more sustainable energy sources has increasingly led researchers to focus on renewable and uncontaminated energy sources [1-4]. Various renewable energy sources are being investigated to assess their potential to address demand on a large scale [5]. These sources include wind turbines, hydroelectric power, wave and tidal power, solar cells, solar thermal energy, etc. [6]. Among these sources, photovoltaic (PV) technology, which uses solar energy, has attracted great attention as a solution to the growing demand for energy [7, 8].

Dye-sensitized solar cells (DSSC) are one of the solar cell technologies that have recently emerged and attracted notable energy research attention [9]. DSSCs offer several advantages, such as low-cost device manufacturing, lightweight, and flexibility compared to conventional silicon-based inorganic solar cells $[10,11]$. Natural dyes can be extracted directly from plants without contamination or tedious synthesis. The separation and purification process 
is relatively simple. It could be achieved using various sensitization with natural dyes to absorb sunlight across the full range of bands [12]. In recent decades, people have carried out extensive research on DSSC sensitized with natural dyes [13].

Metals and semiconductor nanocomposites have been extensively investigated in recent years for their potential applications in photonic devices [14]. Excitation of localized surface plasmon resonance, light trapping, and the ability to act as a cascade of electrons from metal nanocomposites in photoactive DSSC media are the most attractive characteristics of materials that serve as components of the solar absorber [15]. The metal nanocomposite exhibited strong local electromagnetic fields that aided with exciton dissociation and charge mobility, ultimately increasing the device's overall performance $[16,17]$. Several investigations have demonstrated the effects of mono and bimetallic nanocomposites on the processes of optical absorption, exciton dissociation, and charge transport in solar cells [18]. Xolani G. et al. [19] have shown that a trimetallic nanocomposite (Ag: $\mathrm{Zn}$ : Ni) containing $\mathrm{Ag}, \mathrm{Zn}$, and $\mathrm{Ni}$ was successfully synthesized using a wet processing method. They improved the energy conversion efficiencies of the devices by $57 \%$ and $84 \%$ for volume concentrations of $4 \%$ and $6 \%$ of the suspension of the metallic particles, respectively. To the best of our knowledge, there is no literature data reported on the use of trimetallic nanocomposites (TNCs) with CQDs to prepare solar cell devices.

In this work, we used microwave heating in the synthesis processes. The Samsum ant (Pachycondyla sensnaarensi) venom was used as a stabilizing and reducing agent for $\mathrm{Ag} / \mathrm{Ti} / \mathrm{Zn}$ TNPs synthesis and a carbon source for synthesizing carbon quantum dots. The aqueous solutions of proteinaceous venoms produced by ants contain various enzymatic substances, which is ideal for a carbon source in the synthesis of carbon quantum dots [20]. The aqueous solution of this ant venom is antioxidants, so it is used as a reducing agent in the $\mathrm{Ag} / \mathrm{Ti} / \mathrm{Zn}$ TNPs. The nutritional quality of ant venom makes it more effective for synthesizing carbon quantum dots. The microwave-assisted solution pathway represents an efficient wet chemical approach to synthesizing Ag/Ti/Zn TNPs and CQDs NCs, offering additional advantages such as rapid volumetric heating, high reaction rates, size, and shape control by adjusting parameters reaction, and energy efficiency. The use of $\mathrm{Ag} / \mathrm{Ti} / \mathrm{Zn}$ TNPs and CQDs NCs as a dopant in a photoactive layer of Solanum lycopersicum extract mixture showed an improved short-circuit current (Jsc) and a filling factor (FF). UV-Vis, bandgap, SEM, and TEM measurements were also performed to understand the optical and morphological behavior of the Ag/Ti/Zn TNPs and CQDs NCs.

\section{Materials and Methods}

\subsection{Synthesis of Ag/Ti/Zn TNPs.}

The synthesis of Samsum ant (Pachycondyla sensnaarensis) venom-stabilized $\mathrm{Ag} / \mathrm{Ti} / \mathrm{Zn}$ TNPs comprises the following steps: Briefly, the $5 \mathrm{mM}$ silver nitride $\left(\mathrm{AgNO}_{3}\right), 5$ $\mathrm{mM}$ titanium tetrachloride ( $\left.\mathrm{TiCl}_{4}\right)$, and $5 \mathrm{mM}$ zinc chloride $\left(\mathrm{ZnCl}_{2}\right)$ added with stirring in the 1:1:1 ratio in the $50 \mathrm{~mL}$ of water. After that, the $5 \mathrm{~mL}$ of Pachycondyla sensnaarensis venom was then added with stirring in the reaction vessel. The mixture solution was transferred into a Teflon-lined autoclave and treated at a selected temperature of $80^{\circ} \mathrm{C}$ for 20 min under a microwave system. The time for the preparation of TNPs is 2 hours. After that, the residues are filtered through Whatman filter paper. The filtrates were washed and dried at $60^{\circ} \mathrm{C}$ for 3 hours. 
The Samsum ant (Pachycondyla sensnaarensis) venom was used as a reducing agent. Figure 1(a) shows a schematic procedure of synthesis of the Ag/Ti/Zn TNPs.
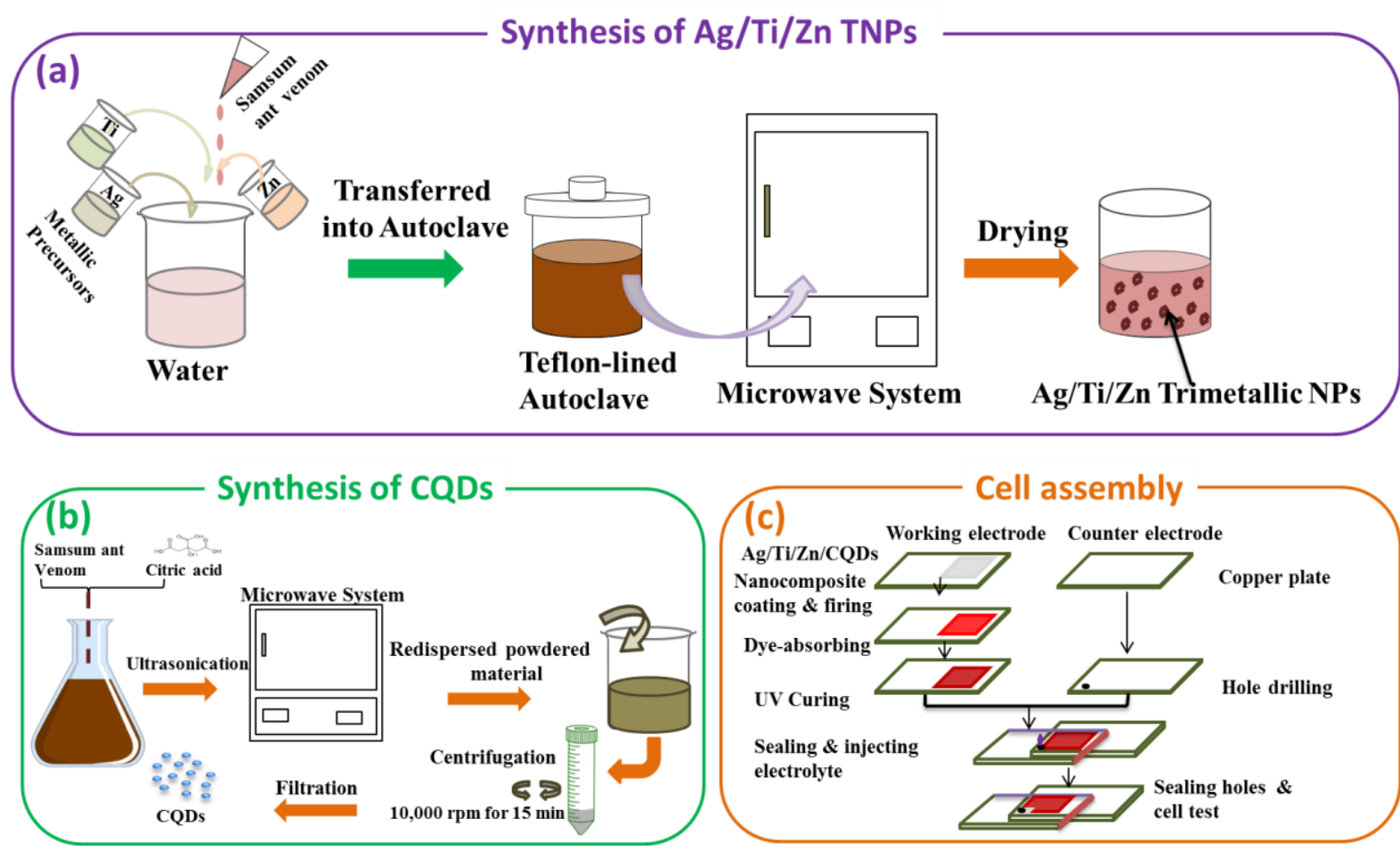

Figure 1. Schematic illustration of (a) synthesis of Ag/Ti/Zn TNPs; (b) synthesis of CQDs; (c) cell assembly.

\subsection{Synthesis of CQDs from Samsum ant (Pachycondyla sensnaarensis) venom.}

The carbon dots were prepared by microwave-assisted rapid synthesis. $1 \mathrm{~g}$ of Samsum ant (Pachycondyla sensnaarensis) venom was dissolved in $15 \mathrm{~mL}$ deionized water under agitation and then mixed with $1 \mathrm{~g}$ citric acid. After ultrasonication for $10 \mathrm{~min}$, the obtained solution was heated for $15 \mathrm{~min}$ in a microwave oven. Following the reaction procedure, the product was cooled down to room temperature and then dissolved in $10 \mathrm{~mL}$ deionized water under stirring to get a brown color solution. Finally, it was centrifuged at 10,000 rpm for $15 \mathrm{~min}$ to remove the impurity and filtered by a filter. The obtained solution was extracted by ethyl acetate and then kept in a refrigerator under $4^{\circ} \mathrm{C}$ for later use. Figure $1(\mathrm{~b})$ represents the schematic procedure of the synthesis of CQDs.

\subsection{Synthesis of Ag/Ti/Zn TNPs and CQDs NCs.}

For the synthesis of $\mathrm{Ag} / \mathrm{Ti} / \mathrm{Zn}$ TNPs and CQDs NCs, the carbon quantum dots (10 ml) and $2 \mathrm{gm}$ of $\mathrm{Ag} / \mathrm{Ti} / \mathrm{Zn}$ TNPs were mixed and kept in the microwave in the cyclic mode for 2 min. Finally, we obtained dark brown color precipitates of $\mathrm{Ag} / \mathrm{Ti} / \mathrm{Zn}$ TNPs and CQDs NCs. Further, these nanocomposites are used as active materials in the solar cell.

\subsection{Preparation of natural dye sensitizers.}

The fruit of Solanum lycopersicum extract contains anthocyanin, $\beta$-carotene, lycopene, and chlorophyll pigment, shows in Figure 2 [21], which is an extraordinary candidate in the fabrication of $\mathrm{Ag} / \mathrm{Ti} / \mathrm{Zn}$ TNPs and CQDs NCs based solar cell. To extract this, rich Solanum lycopersicum fruits were taken and washed several times with water to remove all contaminants. The cleaned Solanum lycopersicum fruit was crushed using mortar and pestle to 
make a paste. Then, $20 \mathrm{~mL}$ of ethanol is added to the Solanum lycopersicum fruit and stirring for $90 \mathrm{~min}$ at $60^{\circ} \mathrm{C}$. The resulting liquid was filtered using filter paper, and the extracted dye was stored for later use. Finally, Ag/Ti/Zn TNPs and CQDs NCs were impregnated with Solanum lycopersicum fruit dye and kept for $10 \mathrm{~h}$.

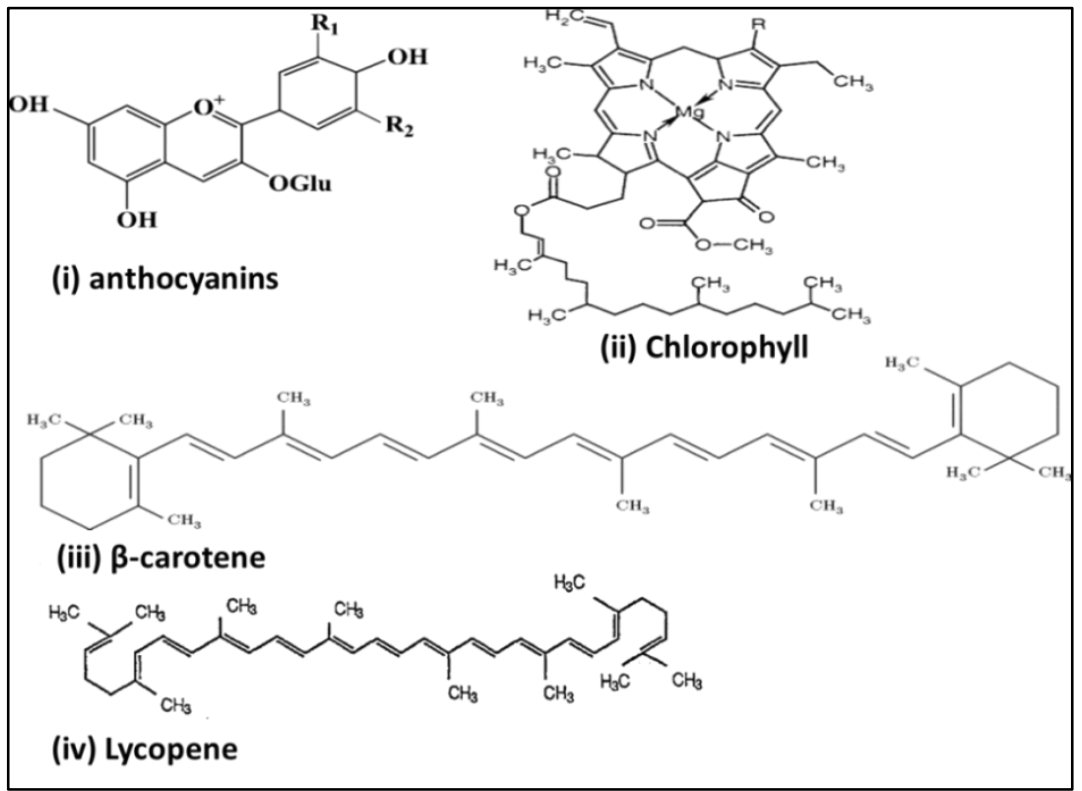

Figure 2. Structure of fruit extract of Solanum lycopersicum pigment compounds.

\subsection{Cell assembly.}

The low-cost copper plate cathode has been an ideal material as a counter electrode. The active layer Ag/Ti/Zn TNPs and CQDs NCs impregnated with natural dyes for $10 \mathrm{hrs}$ are rinsed with absolute ethanol and dried with a hairdryer sandwiched between two electrodes namely FTO and copper plate. The two electrodes were assembled using binders and sealed with a sealing frame. When the electrodes are sealed, two small holes are left open for the polysulfide electrolyte and finally sealed to prevent leakage. The polysulfide electrolyte was prepared by mixing $1 \mathrm{M} \mathrm{Na} 2 \mathrm{~S}, 1 \mathrm{M} \mathrm{S}$, and $0.1 \mathrm{M} \mathrm{NaOH}$ solution in deionized water [22]. A schematic representation of the prepared solar cell is shown in Figures 1(c) and 3.

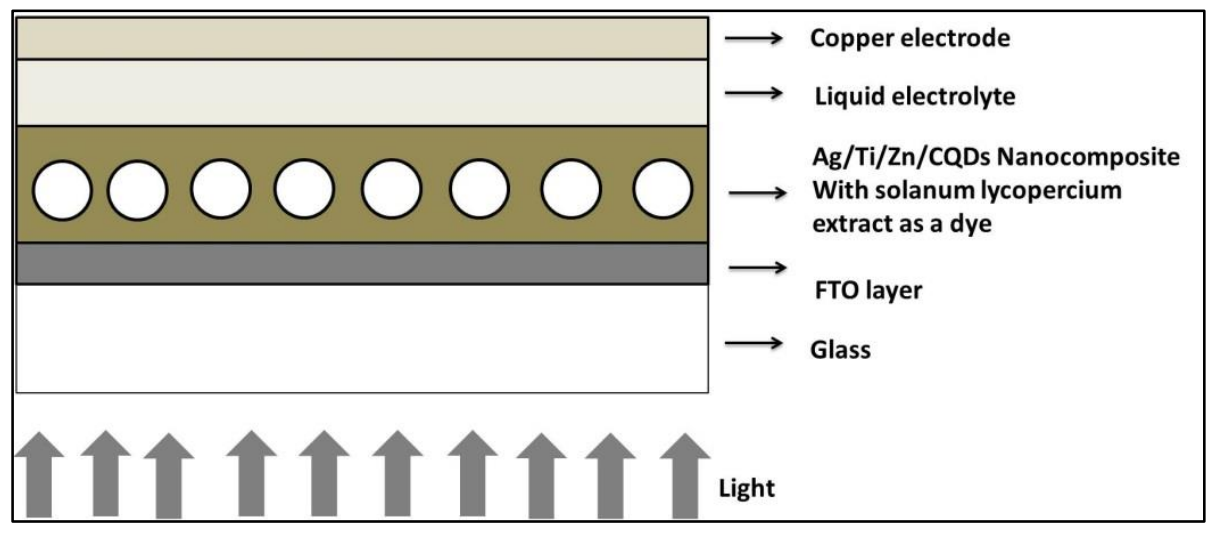

Figure 3. Schematic illustration of the as-fabricated solar cell.

\subsection{Characterization studies.}

The sample's particle shape, size distribution, and microstructure were analyzed using the SEM \& TEM (Tecnai G2 F30 S-TWIN). Optical properties were investigated via UV- 
Visible spectrometry through optical absorbance spectra and ambient temperature transmittance over a 300-800 $\mathrm{nm}$ wavelength range. The optical properties of the FTO substrate with respect to air were taken, and the optical properties of the dye extract in ethanol were taken down by subtracting the effect of the solvent. J-V curves were obtained using Sun $10 \times 10$ digital simulators (AGV Pvt. Ltd.) attached with a computer.

\section{Results and Discussion}

\subsection{Topographical \& morphological studies.}

Transmissions electron microscopy (TEM) provides information about the particle size of the materials. TEM images of Ag/Ti/Zn TNPs and CQDs NCs reveal that the particle size lies in the range of 30-100 nm. In Figure 4(a), the particles stacking can be clearly seen in an image showing the formation of $\mathrm{Ag} / \mathrm{Ti} / \mathrm{Zn}$ TNPs and CQDs NCs.
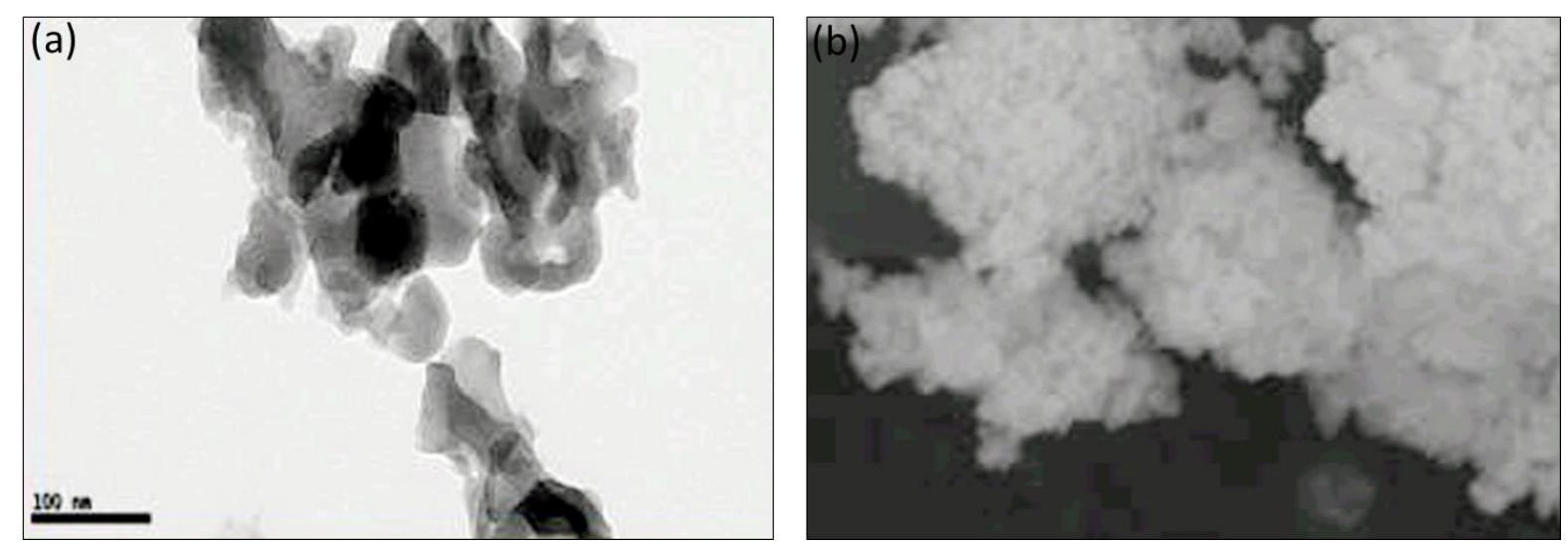

Figure 4. (a) Transmission electron microphotographs of Ag/Ti/Zn TNPs and CQDs NCs; (b) Scanning electron microphotographs of $\mathrm{Ag} / \mathrm{Ti} / \mathrm{Zn}$ TNPs and CQDs NCs.

The synthesized $\mathrm{Ag} / \mathrm{Ti} / \mathrm{Zn}$ TNPs and CQDs NCs were investigated by means of the SEM technique. The SEM images of Ag/Ti/Zn TNPs and CQDs NCs have shown in Figure 4(b) decapitate cluster-based framework of CQDs attached to Ag/Ti/Zn TNPs with having more fibrous morphology confirming binding of trimetallic to CQDs.

\subsection{Optical analysis.}

Improve the performance of the optical properties of the solar cell of each layer is very significant. Therefore, the optical properties of FTO coated as-prepared nanocomposites and dyes are determined using a UV-Vis spectrometer. As FTO thin films are used as conducting films (as FTO glass is used as an electrode) and dye as absorber layer adsorbed on the $\mathrm{Ag} / \mathrm{Ti} / \mathrm{Zn}$ TNPs and CQDs NCs film layer. Therefore, such layers play a vital role in the performance and efficiency of the device due to their versatile optical properties. The absorption spectra of Solanum lycopersicum extract dye coated as-prepared Ag/Ti/Zn TNPs and CQDs (red line), $\mathrm{Ag} / \mathrm{Ti} / \mathrm{Zn}$ TNPs (black line), and Solanum lycopersicum extract dye (green line) were shown

in Figure 5. The absorption spectrum represents the improved light absorption almost double in the Solanum lycopersicum extract dye coated $\mathrm{Ag} / \mathrm{Ti} / \mathrm{Zn}$ TNPs and CQDs NCs compared to pristine Ag/Ti/Zn TNPs. The absorption spectra of the dye from Solanum lycopersicum extract revealed a sharp absorption peak in the UV region, exhibiting a maximum at a wavelength of $375 \mathrm{~nm}$ (low concentration). This result was in agreement with the previous absorption study 
of the wavelength region for the Solanum lycopersicum extract and confirms the presence of anthocyanin, $\beta$-carotene, lycopene, and chlorophyll pigments [9].

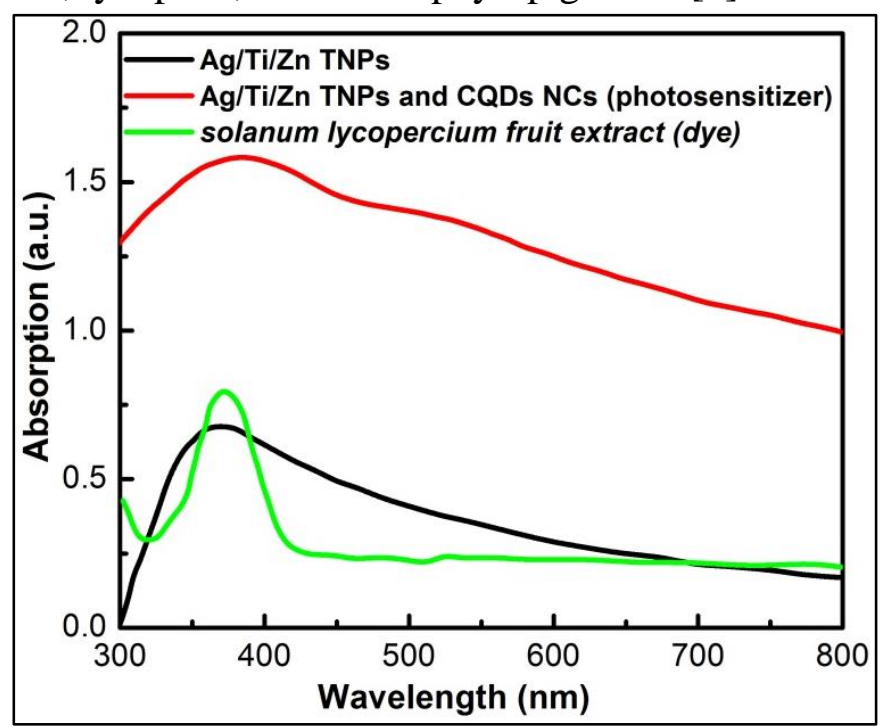

Figure 5. UV-Vis absorption spectrum of Ag/Ti/Zn TNPs (black line); Dye after adsorbed onto the Ag/Ti/Zn

TNPs and CQDs NCs (red line); and fruit of Solanum lycopersicum extract as a dye.

The bandgap of the TNCs and their nanocomposites were calculated by using the Tauc relation shown in Figure 6. The Tauc plots for Ag/Ti/Zn TNPs and Ag/Ti/Zn TNPs and CQDs NCs are represented in Figure 6. The bandgap for Ag/Ti/Zn TNPs is $2.67 \mathrm{eV}$, Figure 6(a), which lies in the semiconductor range $(<4 \mathrm{eV})$. Thus the alloy composed of $\mathrm{Ag}, \mathrm{Ti}$, and $\mathrm{Zn}$ behaves as a semiconductor. So it can find applications in spintronics, thermistors, sensors, and other semiconductor devices. The bandgap of Ag/Ti/Zn TNPs and CQDs NCs Figure 6(b) is $1.75 \mathrm{eV}$. The bandgap of Ag/Ti/Zn TNPs and CQDs NCs is less than Ag/Ti/Zn TNPs.
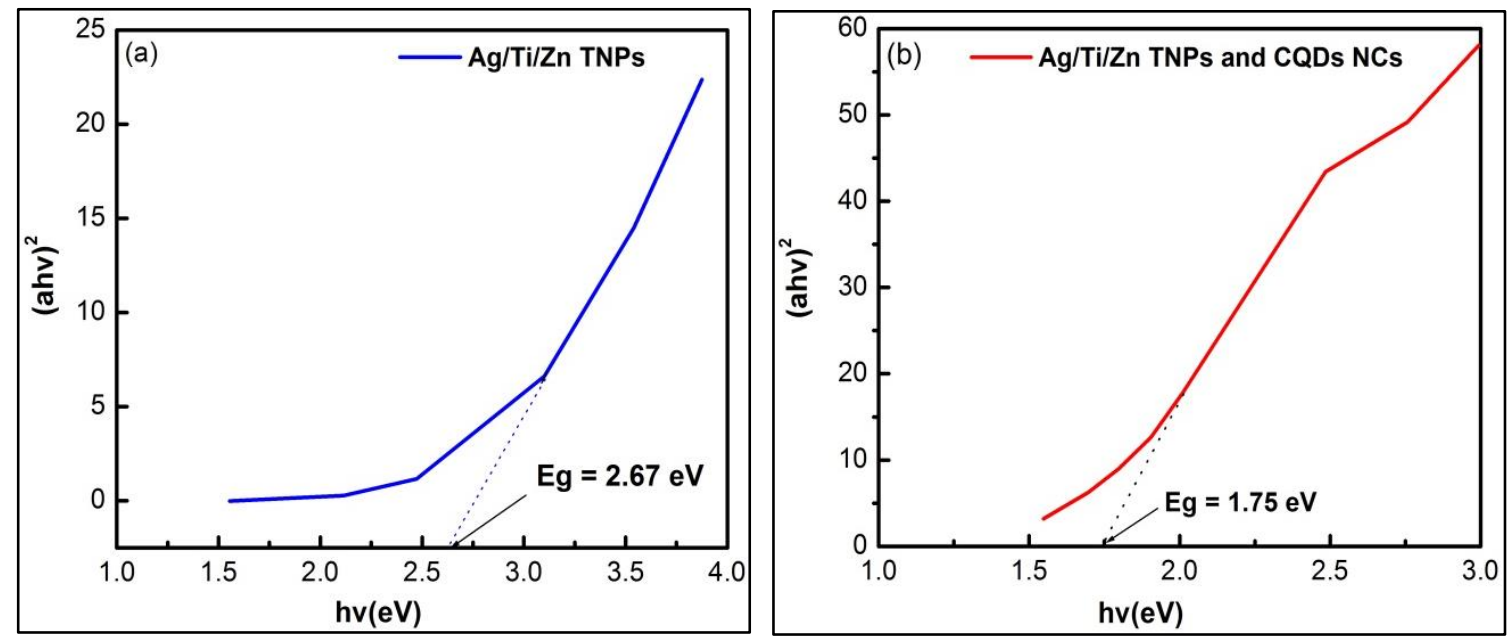

Figure 6. Tauc plot of (a) Ag/Ti/Zn TNPs; (b) Ag/Ti/Zn TNPs and CQDs NCs.

\subsection{Photoelectrical properties.}

Photovoltaic tests of as-prepared solar cells were performed by measuring the Current density-Voltage $(\mathrm{J}-\mathrm{V})$ curves under irradiation with white light $\left(100 \mathrm{~mW} / \mathrm{cm}^{2}\right)$. The performance of natural dye as sensitizers in the solar cell was evaluated by a short circuit (Jsc), open-circuit voltage (Voc), fill factor (FF), and energy conversion efficiency ( $\eta$ ). The electrochemical and electrical losses are taking place while the solar cell operation was 
reflected by the fill factor, i.e., the ratio of maximum to the theoretical power output from the solar cell, which was calculated as [23, 24].

$$
\begin{aligned}
& \mathrm{FF}=\frac{J_{\max } V_{\text {max }}}{J_{s c} V_{o c}} \\
& n=\frac{P_{\text {max }}}{P_{\text {in }}}=\frac{J_{\max } \times V_{\text {max }}}{P_{\text {in }}}=\frac{F F \times\left(V_{o c} \times J_{o c}\right.}{P_{\text {in }}}
\end{aligned}
$$

where $J_{\max }$ is the maximum power point current $\left(\mathrm{mA} / \mathrm{cm}^{2}\right)$, and $\mathrm{V}_{\max }$ is the maximum power point voltage.

The typical J-V curves of the as-prepared solar cell shown in Figure 7, where the illumination of $100 \mathrm{~mW} / \mathrm{cm}^{2}$ light intensity or power input in terms of photoelectric response and photovoltaic examination of the fabricated solar cell was done.

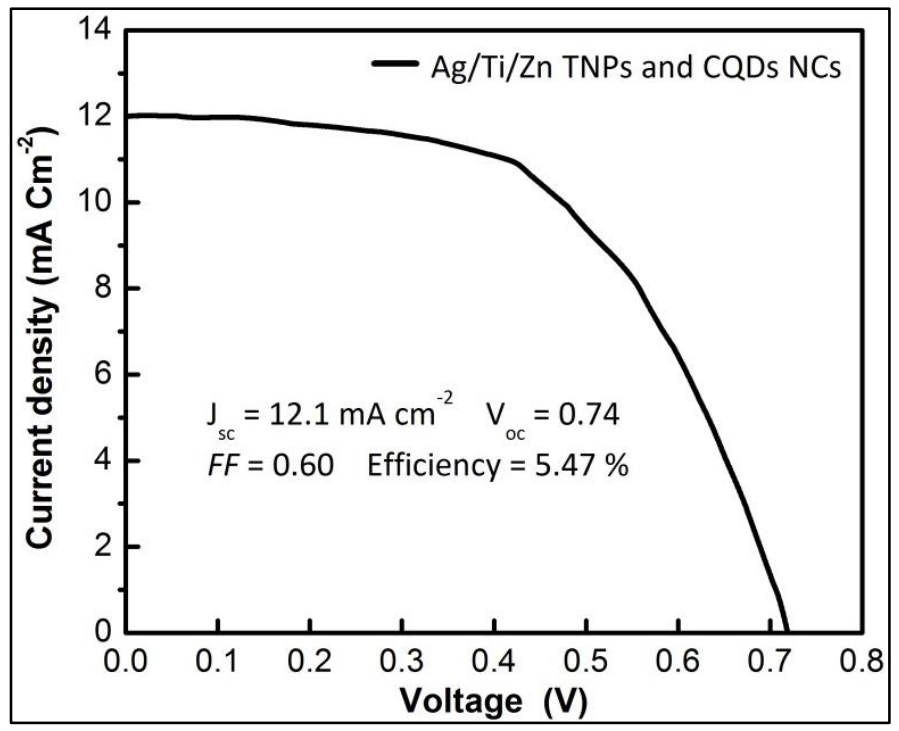

Figure 7. Schematic diagram of J-V plot of Ag/Ti/Zn TNPs and CQDs NCs.

After Solanum lycopersicum fruit extract-based dye solution is adsorbed, it is spread to the relevant Ag/Ti/Zn TNPs and CQDs NCs thin layer. Furthermore, the higher interaction between various pigment molecules in the extracted liquid from Solanum lycopersicum, and $\mathrm{Ag} / \mathrm{Ti} / \mathrm{Zn}$ TNPs and CQDs NCs provides better efficiency and transfers of the charge. The formation and collection of light-generated carriers give the short circuit current density $\left(\mathrm{J}_{\mathrm{sc}}\right)$, while the amount of forwarding bias at the cell junction due to the light-generated current provides an open-circuit voltage $\left(\mathrm{V}_{\text {oc }}\right)$ for a cell. $\mathrm{Ag} / \mathrm{Ti} / \mathrm{Zn}$ TNPs and CQDs NCs in nanoscale provide high surface area because the dye can be absorbed in an interface having a large surface area. At a similar time, it provides a path for electron transfer due to a favorable active interface. The interface resistance of the Ag/Ti/Zn TNPs and CQDs NCs, Solanum lycopersicum dye, and polysulfide electrolyte channel leads to a reduction in short circuit current. The pigment structure of tomato slurry includes anthocyanin, $\beta$-carotene, lycopene, chlorophyll, and the $\mathrm{Ag} / \mathrm{Ti} / \mathrm{Zn}$ TNPs and CQDs NCs responsible for making as-prepared solar cells more efficient than normal dye-based solar cells.

\section{Conclusions}

The CQDs and Ag/Ti/Zn NPs were synthesized by microwave-assisted preparation using Samsum ant (Pachycondyla sensnaarensis) venom as both a carbon source and a reducing agent. As far as we know, there are no literature data on the synthesis for this kind of 
material for this application. The $\mathrm{Ag} / \mathrm{Ti} / \mathrm{Zn}$ TNPs and CQDs NCs were fabricated by microwave-assisted greener synthesis, which was used as a photosensitizer, the copper plate as a counter electrode, and polysulfide as an electrolyte was assembled into the solar cell. We have studied the SEM and TEM analysis for size, morphological and topographical analysis. Optical properties of $\mathrm{Ag} / \mathrm{Ti} / \mathrm{Zn}$ TNPs and CQDs NCs showed broadband of absorbance from $300 \mathrm{~nm}$ to $700 \mathrm{~nm}$ wavelength covering most of the visible region. The J-V measurement made on our as-prepared solar cell shows the interesting values of short current $\left(\mathrm{J}_{\mathrm{sc}}\right)$, open-circuit voltage $\left(\mathrm{V}_{\mathrm{oc}}\right)$, fill factor $(\mathrm{FF})$, and efficiency $(\eta)$, which are $12.1 \mathrm{~mA} / \mathrm{cm}^{2}, 0.74 \mathrm{~V}, 0.60$, and $5.47 \%$ respectively.

\section{Funding}

This research received no external funding.

\section{Acknowledgments}

The authors declare no acknowledgments

\section{Conflicts of Interest}

The authors declare no conflict of interest.

\section{References}

1. Rajesh, K.C.J.; Majid, M.A. Renewable energy for sustainable development in India: current status, future prospects, challenges, employment, and investment opportunities. Energy, Sustainability and Society 2020, 10, https://doi.org/10.1186/s13705-019-0232-1.

2. Salvarli, S.S.; Salvarli, H. For Sustainable Development: Future Trends in Renewable Energy and Enabling Technologies. 2019, https://doi.org/10.5772/intechopen.91842.

3. Flavio, R.A.R.; Miguel, L.J. The Role of Renewable Energies for the Sustainable Energy Governance and Environmental Policies for the Mitigation of Climate Change in Ecuador. Energies 2020, 13, https://doi.org/10.3390/en13153883.

4. Wang, Q.; Wang, Q.; Wei, Y.-M.; Li, Z.-P. Role of renewable energy in China's energy security and climate change mitigation: An index decomposition analysis. Renew. Sustain. Energy Rev. 2018, 90, 187-194, https://doi.org/10.1016/j.rser.2018.03.012.

5. Gielen, D.; Boshell, F.; Saygin, D.; Bazilian, M.D.; Wagner, N.; Gorini, R. The role of renewable energy in the global energy transformation. Energy Strategy Reviews 2019, 24, 38-50, https://doi.org/10.1016/j.esr.2019.01.006.

6. Owusu, P.A.; Sarkodie, S.A. A review of renewable energy sources, sustainability issues and climate change mitigation. Cogent Engineering 2016, 3, https://doi.org/10.1080/23311916.2016.1167990.

7. Kannan. N.; Vakeesan, D. Solar energy for future world: - A review. Renewable and Sustainable Energy Reviews 2016, 62,1092-1105, https://doi.org/10.1016/j.rser.2016.05.022.

8. Pala, J.; Mordiya, M.; Virpariya, D.; Dangodara, A.; Gandha, P.; Savaliya, C.R.; Joseph, J.; Shiyani, T.; Dhruv, D.; Markna, J.H. Analysis and design optimization of organic dye sensitized solar cell based on simulation. AIP Conference Proceedings 2017, 1837, 030004, https://doi.org/10.1063/1.4982082.

9. Moradiya, M.; Dangodara, A.; Pala, J.; Savaliya, C.R.; Dhruv, D.; Rathod, V.R.; Joshi, A.D.; N.A. Shah, N.A.; Pandya, D.; Markna, J.H. A natural tomato slurry as a photosensitizer for dye-sensitized solar cells with $\mathrm{TiO} 2 / \mathrm{CuO}$ composite thin films. Separation Science and Technology 2019, 54, 207-212, https://doi.org/10.1080/01496395.2018.1444053.

10. Ho, S.M.; Mariyappan, S.; Meet, M.; Markana, J.H. Review on dye-sensitized solar cells based on polymer electrolytes. International Journal of Engineering \& Technology 2018, 7, https://doi.org/10.14419/ijet.v7i4.14041. 
11. Shiyani, T.; Bagchi, T. Hybrid nanostructures for solar-energy-conversion applications. Nanomaterials and Energy 2020, 9, https://doi.org/10.1680/jnaen.19.00029.

12. Shiyani, T.; Mahapatra, S.K.; Bogle, K.A.; Banerjee, I. Biohybrid electrodes for photoelectrochemical solar energy conversion. Journal of Renewable and Sustainable Energy 2020, 12, 044701, https://doi.org/10.1063/5.0015139.

13. Shiyani, T.; Mahapatra, S.K.; Banerjee, I. Natural Basil as Photosensitizer with ZnO Thin Films for Solar Cell Applications. IETE Journal of Research 2020, https://doi.org/10.1080/03772063.2020.1768161.

14. Khiriya, P.K.; Moradiya, M.A.; Khare, P.S. Development of Fe/Ru Bimetallic Nanoparticles for Promising Application in the Selective synthesis of SWNTs. Mat Int 2020, 2, 0250-0255, https://doi.org/10.33263/Materials22.250255.

15. Uddin, M.J.; Islam, J.M.M.; Rahman, M.A.; Khan, M.A. Development of Photoactive Titanium Dioxide Doped Sodium Alginate Film for Dye Sensitized Solar Cell Application. International Journal of Thin Films Science and Technology 2017, 6, 135-138, https://doi.org/10.18576/ijtfst/060307.

16. Elumalai, N.K.; Vijila, C.; Jose, R.; Uddin, R.; Ramakrishna, S. Metal oxide semiconducting interfacial layers for photovoltaic and photocatalytic applications. Materials for Renewable and Sustainable Energy 2015, 4, https://doi.org/10.1007/s40243-015-0054-9.

17. Feng, L.; Niu, M.; Wen, Z.; Hao, X. Recent Advances of Plasmonic Organic Solar Cells: Photophysical Investigations. Polymers, 2018, 10, 123, https://doi.org/polym10020123.

18. Oseni, S.O.; Mola, G, T. Bimetallic nanocomposites and the performance of inverted organic solar cell. Composites Part B: Engineering 2019, 172, 660-665, https://doi.org/10.1016/j.compositesb.2019.05.084.

19. Mbuyise, X. G.; Arbabab, E. A. A.; Mola, G, T. The effect of a trimetallic nanocomposite in the solar absorber layer of organic solar cells. RSC Advances 2019, 9, 6070-6076, https://doi.org/10.1039/c8ra08725c.

20. Torres, A.F.C.; Quinet, Y. P.; Havt, A.; Rádis-Baptista, G.; Martins, A.M.C. Molecular Pharmacology and Toxinology of Venom from Ants. In An Integrated View of the Molecular Recognition and Toxinology - From Analytical Procedures to Biomedical Applications, 2013, https://doi.org/10.5772/53539.

21. Arthanari, M.; Dhanapalan, S. Quantifcation of $\beta$-carotene, lycopene, and chlorophyll content in tomato fruits of enrichment of chicken feathers composting. International Journal of Recycling of Organic Waste in Agriculture 2019, 8, 473-477 https://doi.org/10.1007/s40093-019-0258-6.

22. Yaacob, K.A.; Ishak, M.N.; Alias, N.N. Quantum Dots Sensitized Solar Cell: Effect of CdSe Nanoparticles Purification Procedure of QD Sensitized Photoanodes. Journal of Physics: Conference Series 2013, 431, https://doi.org/10.1088/1742-6596/431/1/012019.

23. Jao, M.; Liao, H.; Su, W. Achieving High Fill Factor of Organic Solar Cell. Journal of Materials Chemistry A 2016, https://doi.org/10.1039/C6TA00126B.

24. Sharma, D.K.; Purohit, G. Analysis of the Effect of Fill Factor on the Efficiency of Solar PV System for Improved Design of MPPT. 6th World Conference on Photovoltaic Energy Conversion (WCPEC-6), Kyoto, Japan, 2014. 